\title{
EDUCAÇÃO AMBIENTAL POR MEIO DE TRILHAS ECOLÓGICAS INTERPRETATIVAS COM ALUNOS NEES
}

\author{
Mariane Cyrino dos Santos'; Mônica Dutra Flores²; Elisabete Maria Zanin³ \\ ${ }^{1}$ Bióloga, articuladora social do Núcleo de Sustentabilidade de Machadinho, marianecyrino@gmail.com; \\ ${ }^{2}$ Acadêmica do Curso de Ciências Biológicas da Universidade Regional Integrada do Alto Uruguai e das Missões - \\ Campus de Erechim, monikinhaflores@hotmail.com ; \\ ${ }^{3}$ Professora Doutora do Curso de Ciências Biológicas da Universidade Regional Integrada do Alto Uruguai e das \\ Missões - Campus de Erechim, emz@uricer.edu.br ;
}

\section{RESUMO}

O presente trabalho visou aperfeiçoar a interação de alunos com Necessidades Educativas Especiais (NEEs), com o meio ambiente, proporcionando a participação destes em atividades lúdicas com o intuito de melhorar a relação dos mesmos com o ambiente que os cerca. $O$ projeto foi desenvolvido na Escola Municipal de Educação Especial Branca de Neve - APAE de Erechim/RS no período de agosto de 2009 a julho de 2011. Utilizou-se de Trilhas Interpretativas como instrumento básico de promoção de um processo de aprendizagem e sensibilização sobre temas relacionados ao meio ambiente e conservação de áreas naturais interligados a inclusão social. Buscou também oportunizar vivências na natureza para um melhor desenvolvimento cognitivo. Ao longo da trilha autoguiada, foram enfocados diferentes elementos bióticos e abióticos e suas interrelações no ecossistema, destacando-se a importância da Floresta Ombrófila Mista e da vegetação ribeirinha na proteção do córrego existente na área. As atividades realizaram-se em pequenos grupos, distribuídos conforme a idade mental do público alvo e, organizadas com materiais concretos. Os registros, destas atividades, pelos indivíduos NEEs foram na forma de: desenhos, pinturas, colagem, modelagem, comunicação oral, cantos e dramatizações. O uso de Trilhas Interpretativas como instrumento pedagógico para a educação ambiental na APAE de Erechim, proporcionou uma maior aproximação dos alunos Portadores de Necessidades Educativas Especiais (NEEs) com o meio natural e com os próprios colegas, contribuindo assim com o desenvolvimento afetivo e emocional dos mesmos, permitindo a efetivação de um processo educativo ambiental dinâmico. A Educação Ambiental para uma pessoa com algum tipo de necessidade especial tem os mesmos objetivos e deve seguir os princípios de uma Educação Inclusiva, ou seja, adequar o ensino a realidade do educando, possibilitando a ele uma melhor compreensão dos assuntos abordados e sua relação com o contexto social em que vive. É possível observar que nas atividades realizadas ao ar livre os alunos com NEEs interagem com o meio ambiente de forma positiva, pois neste local são eliminadas as barreiras físicas ou de comunicação. Conclui-se que as trilhas, devido a sua natureza interdisciplinar, possibilitam ganhos as mais variadas áreas do conhecimento, sendo muito importantes para a formação dos alunos.

Palavras-chave: processos educativos; sensibilização ambiental; atividades lúdicas; educandos NEEs.

\section{ABSTRACT}

This study aims to improve the interaction of students with Special Educational Needs (Nees), with the environment, providing their involvement in recreational activities in order to improve their 
relation with the environment around them. The project was developed at the Municipal School of Special Education Snow White - APAE Erechim / RS from August 2009 to July 2011. We used the trails as a basic instrument to promote a process of learning and awareness on issues related to environment and conservation of natural areas linked to social inclusion. Also sought to create opportunities to experience nature in a better cognitive development. Along the trail self-guided, were focused on different biotic and abiotic factors and their interrelationships in the ecosystem, highlighting the importance of Araucaria forest and riparian vegetation to protect the existing stream in the area. The activities were held in small groups, distributed according to the mental age of the target audience, and organized with concrete materials. The records of these activities, individuals Nees were in the form of: drawings, paintings, collage, modeling, speaking, singing and drama. The use of trails as an educational tool for environmental education in APAE Erechim, provided a closer approximation of pupils with Special Educational Needs (Nees) with the natural environment and their own colleagues, thereby contributing to the development of affective and emotional same, allowing the realization of a dynamic environmental education process. Environmental education for a person with some kind of special need have the same goals and should follow the principles of inclusive education, ie teaching fit the reality of the student, providing him a better understanding of the issues discussed and their relationship with the social context in which they live. You can see that in outdoor activities with the students Nees interact with the environment in a positive way, because this site are eliminated and the physical barriers of communication. It is concluded that the tracks due to its interdisciplinary nature, allow gains the most varied areas of knowledge and it is very important for the formation of students.

Keywords: educational processes, environmental awareness, recreational activities, students Nees.

\section{INTRODUÇÃO}

Com as crescentes pressões humanas nos ambientes naturais, a Educação Ambiental tornase cada vez mais importante e apresenta-se como um meio de buscar apoio e participação dos diversos segmentos da sociedade para a conservação e a melhoria da qualidade de vida. A Educação Ambiental propicia o aumento de conhecimentos, mudanças de valores e o aperfeiçoamento de habilidades, que são condições básicas para que o ser humano assuma atitudes e comportamentos que estejam em harmonia com o meio ambiente (PADUA e TABANEZ, 1997).

Segundo VASCONCELLOS (1997), a presença, em todas as práticas educativas, da reflexão sobre as relações dos seres entre si, do ser humano com ele mesmo e do ser humano com seus semelhantes é condição imprescindível para que a Educação Ambiental ocorra. Dentro desse contexto, sobressaem-se as escolas, como espaços privilegiados na implementação de atividades que propiciem essa reflexão, pois isso necessita de atividades de sala de aula e atividades de campo, com ações orientadas em projetos e em processos de participação que levem à autoconfiança, à atitudes positivas e ao comprometimento pessoal com a proteção ambiental implementados de modo interdisciplinar (DIAS, 1992).

Segundo Mello (2006), um método importante na Educação Ambiental é transformar a teoria da sala de aula em prática, usando os recursos ecológicos, na qual se destacam as trilhas interpretativas. Estas são utilizadas com freqüência em projetos como meio de interpretação 
ambiental visando não somente a transmissão de conhecimentos, mas também propiciando atividades que analisam os significados dos eventos observados no ambiente bem como as características do mesmo (ZANIN, 2006). Além de propiciar o contato com a natureza, o descanso, a fruição são também meios eficazes na interação homem/natureza e podem contribuir na formação da consciência ambiental (SIQUEIRA, 2004).

Para Dias e Zanin (2004) as trilhas traduzem para o aluno visitante das áreas naturais, os fatores que estão além das aparências, como as leis naturais, interações, funcionamento, história ou fatos, que, mesmo que evidentes, não são comumente percebidos por quem está caminhando por elas.

A educação ambiental possibilita a formação de valores e atitudes sensíveis à diversidade, à complexidade e à solidariedade diante dos outros seres humanos e da natureza (CARVALHO, 1998). Portanto, é necessário não só oferecer informações, como também propor experiências que reconstruam a conexão entre o ser humano e a natureza (TOMAZELLO \& FERREIRA, 2001).

A acessibilidade em todos os níveis torna-se indispensável à inclusão de todas as pessoas na sociedade da informação e do conhecimento, portanto os indivíduos Portadores de Necessidades Educativas Especiais (NEEs) têm tanto direito de aproveitar recursos educativos quanto as pessoas fisicamente aptas.

A integração dos Portadores de Deficiência, atualmente chamadas NEEs, tem sido a proposta norteadora e dominante na Educação Especial, direcionando programas, políticas educacionais e de reabilitação (BATISTA, et al., 2004).

$O$ presente trabalho pretende relatar um projeto de extensão desenvolvido na Escola de Educação Especial Branca de Neve - APAE de Erechim/RS. Teve por objetivos aperfeiçoar a interação de alunos com Necessidades Educativas Especiais (NEEs) com o meio ambiente, proporcionando a participação destes em atividades lúdicas com o intuito de melhorar a relação dos mesmos com o ambiente que os cerca. Buscou também oportunizar vivências na natureza para um melhor desenvolvimento cognitivo.

\section{METODOLOGIA}

O trabalho de Educação Ambiental proposto foi realizado na Escola de Educação Especial Branca de Neve - APAE - localizada no município de Erechim/ RS (Fig 01). Esta escola foi criada em 1967 e atualmente atende 250 indivíduos Portadores de Necessidades Educativas Especiais (NEEs) da região do Alto Uruguai Gaúcho.

Projetos de extensão são realizados na escola de Educação Especial Branca de Neve, desde 2003, quando foi implantada uma trilha interpretativa na área verde de 15 ha, disponível na escola. Os alunos elegeram a Joaninha como espécie símbolo da área e denominaram o caminho implantado de Trilha da Joaninha (Fig 02). A trilha possui 300 metros de extensão.

Ao longo da trilha autoguiada, são enfocados diferentes elementos bióticos e abióticos e suas inter-relações no ecossistema, destacando-se a importância da Floresta Ombrófila Mista e da vegetação ribeirinha na proteção do córrego existente na área. 


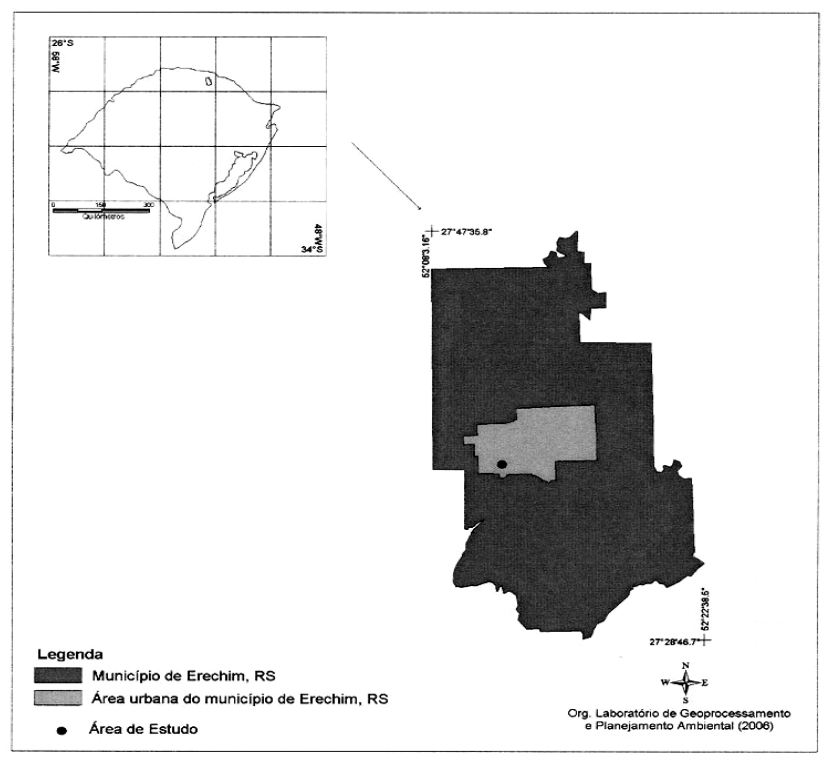

Figura 01 - Localização geográfica da área de estudo.

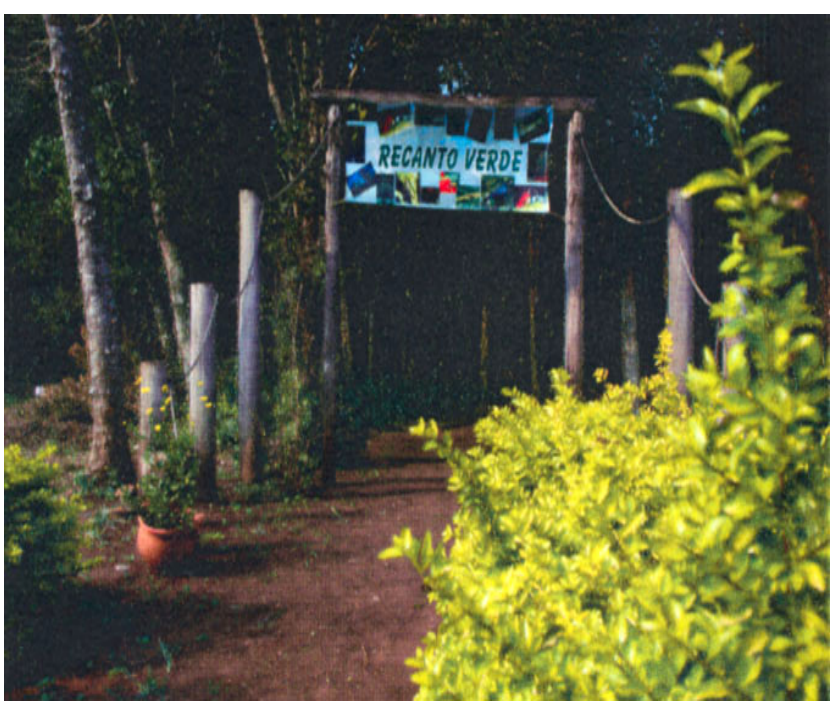

Figura 02: Recanto Verde da APAE - Pórtico de entrada da Trilha Interpretativa.

Os procedimentos metodológicos adotados para a execução do plano de trabalho incluíram a revisão teórica, por meio de leituras e fichamento de ideias sobre os temas: educação ambiental, interpretação ambiental e trilhas interpretativas; acessibilidade e inteligências múltiplas. Posteriormente houve o diagnóstico das necessidades educativas apresentadas pelos alunos e os métodos psicopedagógicos adequados para os casos. Reuniões de estudo e planejamento foram realizadas para a construção de uma base teórica que fundamentasse a elaboração dos planos de atividads lúdico-pedagógicas capazes de desenvolver as múltiplas inteligências.

Para o desenvolvimento do trabalho foram criados roteiros interpretativos coerentes e eficientes, baseados nos diferentes aspectos existentes ao longo das trilhas e nas principais 
informações e conceitos que se deseja transmitir. Para tanto, foram definidos os temas a serem interpretados que estimulem a observação, a reflexão e a ação.

Os roteiros interpretativos e os planos de atividades lúdico-pedagógicas elaborados e colocados em desenvolvimento foram relacionados com os temas de interesse dos alunos e da escola, sendo eles: Água e Vida (- As fontes de água potável; - Preservação da água; - Uso econômico da água); Meio Ambiente (- Relações Ecológicas; - Cadeias e teias alimentares; Conservação de fauna e flora;) e Plantas Medicinais (- Plantio de mudas; - Colheita das plantas medicinais; - Estudo sobre a importância das plantas medicinais). Estas atividades pedagógicas auxiliaram na aquisição de conhecimentos bem como auxiliaram no desenvolvimento de habilidades sensoriais e motoras. Todas as atividades foram realizadas em contato com a natureza promovendo a sensibilização nessa integração entre ambiente e alunos.

O projeto "Trilhas Interpretativas para Educandos Portadores de Necessidades Educativas Especiais Múltiplas Trilhas e Avaliação da Eficiência" leva à escola e aos alunos portadores de necessidade especiais (NEEs) os princípios, os valores e as atitudes que estão na base da educação ambiental, articulando as relações entre homem e natureza ou natureza e cultura, contribuindo desta forma, para a mudança da mentalidade e do comportamento concreto das pessoas nos diferentes espaços sócio-ambiental.

Busca também a constituição de uma base suficientemente sólida relacionando pesquisa, extensão e ensino para o eficiente desenvolvimento da dimensão educativa inclusiva, pretendendo articular a experiência adquirida em pesquisas e estudos com um planejamento sócio-político que seja verdadeiramente condizente com as necessidades locais dos indivíduos NEEs. Desde 2003, quando implantada essa trilha interpretativa nas ações de educação ambiental na Escola de Educação Especial Branca de Neve (APAE) de Erechim/RS, já foram contemplados 250 educandos NEEs, professores, pais e comunidade do entorno escolar.

O projeto utiliza a Trilha da Joaninha e outras trilhas temporárias para realizar atividades de Interpretação e Educação Ambiental, pois estas emergem como instrumento significativo na tomada de consciência ambiental, promovendo reflexões sobre as relações entre o ser humano e o meio ambiente. Os recursos presentes na trilha bem como o anfiteatro natural instalado na parte que antecede o caminho da trilha, também são utilizados para a execução de atividades lúdico-pedagógicas, objetivando o desenvolvimento das múltiplas inteligências (musical, lógicomatemático, espacial, interpessoal, intrapessoal, lingüística e cinestésica) propostas por Gardner (1995).

\section{RESULTADOS}

As trilhas, como meio de interpretação ambiental, visam não somente a transmissão de conhecimento, mas também propiciam atividades que revelam os significados e as características do ambiente por meio de usos dos elementos originais, por experiência direta e por meios ilustrativos, sendo assim, encaixa-se como um instrumento básico de educação ambiental.

Foram elaborados planos de atividades lúdico-pedagógicas, educativas e recreativas, abrangendo temas relacionados ao meio ambiente e sua conservação, tendo como base o Projeto Pedagógico da Escola Branca de Neve em um trabalho conjunto com professores e acadêmicos voluntários.

As atividades receberam os seguintes temas: I - "Salvem Plantas que salvam vidas" (Projeto plantas medicinais) - Trilha das plantas medicinais; II - "Epífitas: as hospedeiras das árvores" - Trilha da Joaninha; III - "Retrospectiva das atividades realizadas em 2009" - Trilha do 
conhecimento; IV - "Natal tempo de reflexão" - Trilha dos Reis Magos; V - Formigas e Importância Ecológica - Trilha das Formigas; VI - Dia Mundial da Água - Trilha da água; VII - Projeto Meio Ambiente 2010 - Trilha do Meio Ambiente; VII - "Trilha dos sentidos: autoconhecimento" com a Trilha da Joaninha: Um mundo de Sensações; IX - “A importância de uma boa alimentação" com a Trilha - Alimentação Saudável; X - "As Flores e Frutos" com a Trilha - Conhecendo e preservando as plantinhas; XI - "Importância das plantas medicinais" com a Trilha - As plantinhas na nossa Vida; XII - "Conservação dos animais" com a Trilha - Animais e suas funções no ambiente; XIII "Preservação e conservação ambiental" com a Trilha - Nosso meio ambiente e a nossa vida.

O uso de plantas medicinais no tratamento das mais diversas doenças ocorre desde os tempos mais remotos da história do homem. O Projeto Plantas Medicinais teve por objetivo estudar as propriedades das ervas medicinais. Através de um teatro de fantoches foi introduzido o estudo das plantas medicinais. Esta atividade contou com a presença de uma palestrante da URI (Fig 03). Os alunos participaram desta atividade contando que já conheciam algumas plantas medicinais e que suas mães faziam chás quando estavam com algum problema. Ao final desta atividade foram feitos saches de chá de carqueja e cavalinha para os alunos levarem para casa.

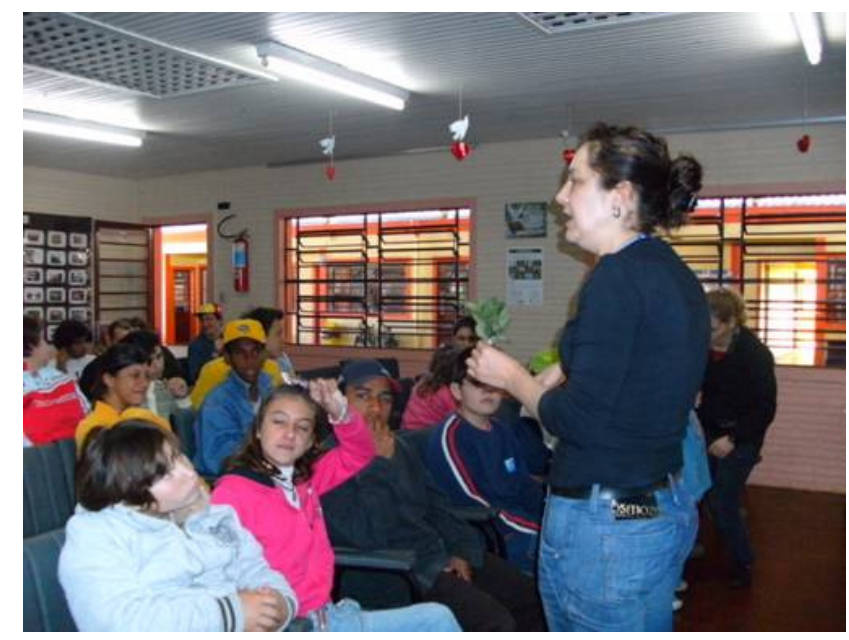

Figura 03: Palestra sobre as plantas medicinais. Trilha das Plantas Medicinais.

$\mathrm{Na}$ Trilha da Joaninha trabalhamos com as Epífitas as Hospedeiras das árvores (Figura 04). Nesta atividade os alunos foram levados até a área verde da escola onde percorreram a trilha para visualizar estas plantas por vezes desconhecidas. 


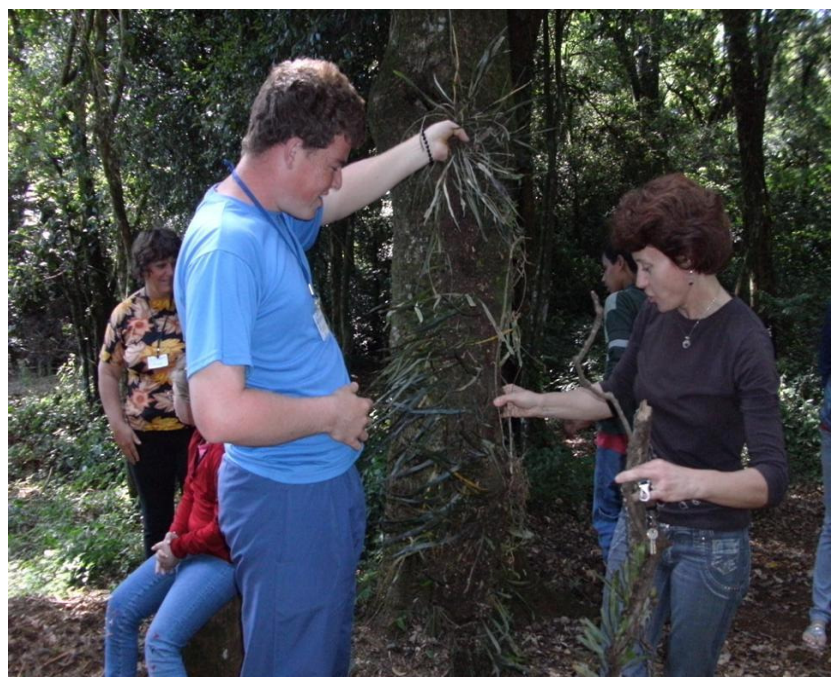

Figura 04: Epífitas as Hospedeiras das Árvores - Trilha da Joaninha.

O Projeto Meio Ambiente teve por objetivos vivenciar na prática atitudes de conservação do meio ambiente; construir um miniviveiro de mudas de araucária para futuro plantio e utilizar novas tecnologias de informação e conhecimento para avaliação e feedback das atividades sobre meio ambiente. Neste projeto foram feitas algumas atividades, dentre elas, plantio de sementes de araucária em garrafas pet (Figura 05); visita a Trilha da Joaninha (Figura 06); plantio de ervas cheirosas nos vasos para utilizar no jardim dos sentidos; reconstrução do auditório da Trilha e do Jardim dos Sentidos; organização dos canteiros do relógio do corpo humano e plantio de plantas medicinais; construção de um minhocário na horta.

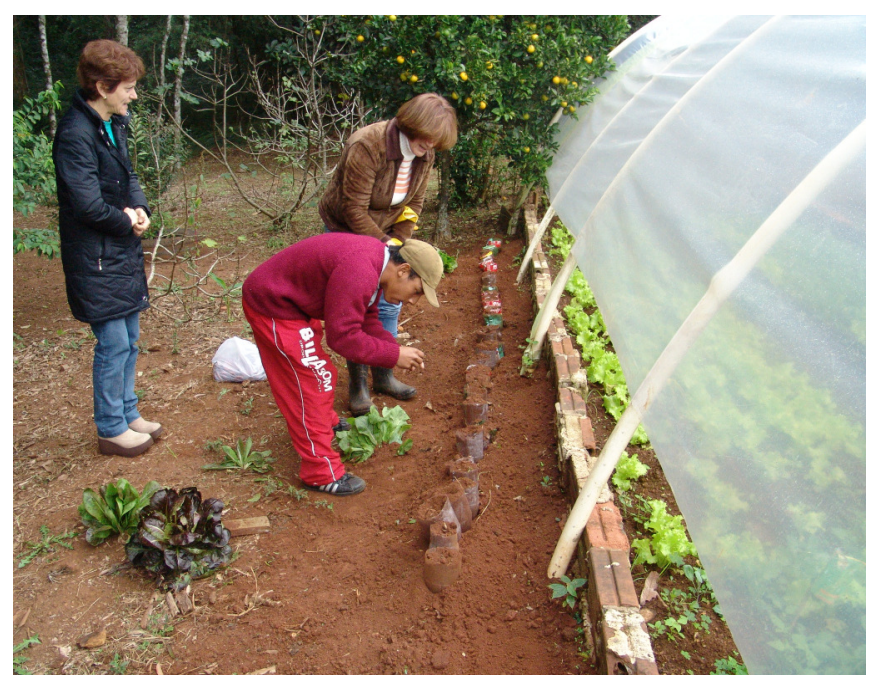

Figura 05: Plantio de sementes de araucária em garrafas pet. 


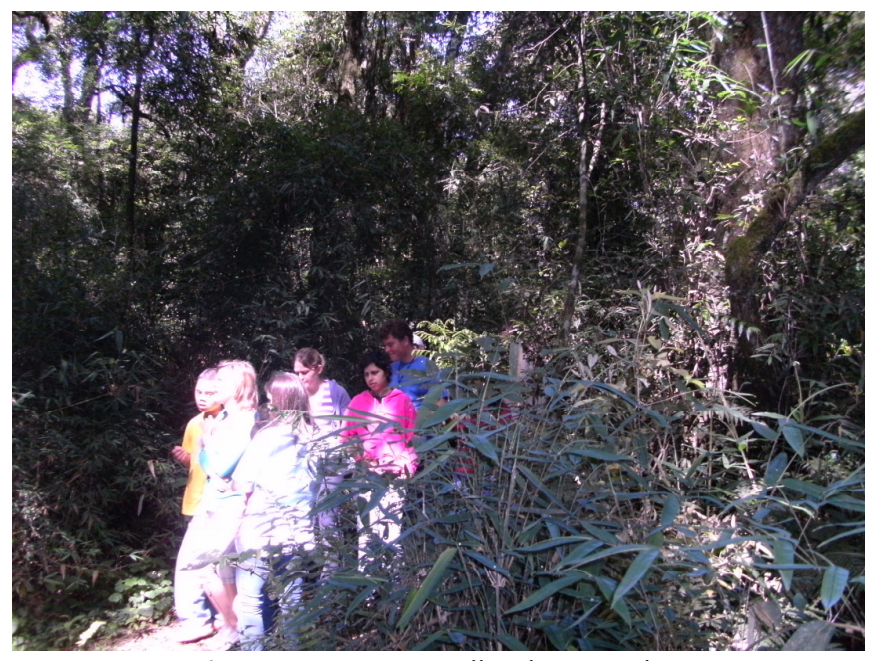

Figura 06: Visita a Trilha da Joaninha.

$\mathrm{Na}$ "Trilha dos sentidos, se auto conhecendo" (Figura 07 e 08), foi trabalhado os sentidos, coordenação motora, fauna, flora, meio ambiente e relações ecológicas. A trilha foi denominada como "Trilha da Joaninha - Um mundo de sensações". A trilha foi composta por 10 pontos diferentes, incluindo plantas, musgos, fungos, animais e outros a qual foi instalada na trilha da joaninha, área verde da Escola Branca de Neve. As trilhas dos sentidos tem como objetivo principal, aproximar os alunos da natureza, do meio ambiente em geral, despertando nos mesmo, o respeito pela natureza como um todo, aprendendo assim a respeitar e cuidar de todos os seres vivos, seja ele animal ou vegetal.

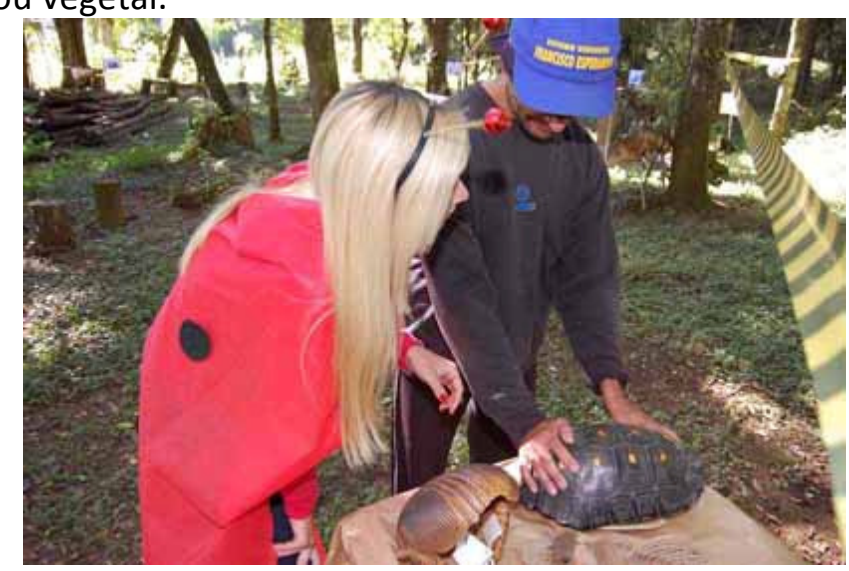

Figura 07: "Trilha da Joaninha - Um mundo de sensações" 


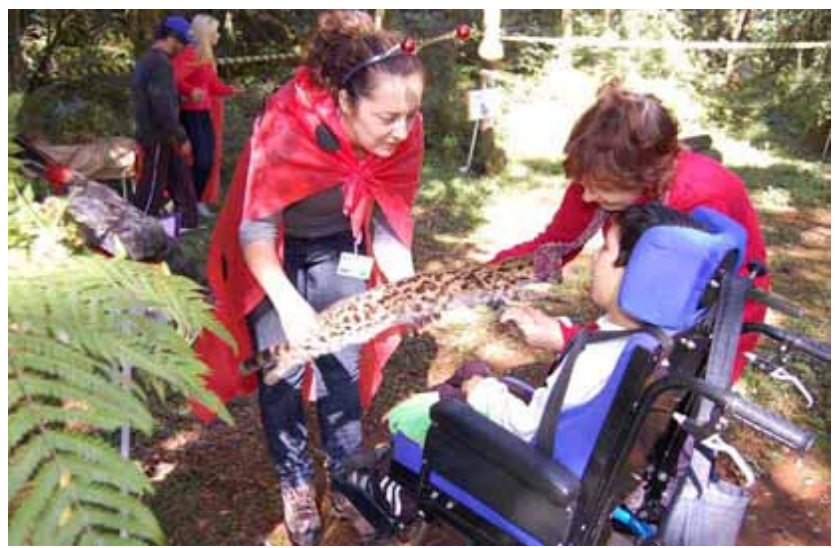

Figura 08: "Trilha da Joaninha - Um mundo de sensações"

Com os trabalhos desenvolvidos por meio das trilhas ecológicas interpretativas percebeuse uma maior interação dos alunos com a natureza, por meio da percepção de detalhes não vistos e abordados em ações normais de visitas à floresta, motivando o participante a usar sua criatividade e provocar atitudes capazes de, na prática, desenvolver uma consciência mais voltada à conservação do ambiente.

Nas atividades realizadas ao ar livre os alunos NEEs interagem com o meio ambiente de forma positiva, pois neste local são eliminadas as barreiras físicas ou de comunicação. Além disto, trata-se de um processo de socialização que leva ao reencontro com a natureza e à identificação do sentido de pertinência em relação ao próprio grupo de trabalho de forma cooperativa, integradora e inclusiva.

Foi possível observar que os educandos NEEs assimilaram conceitos trabalhados desde o início do projeto, tendo havido, desta forma, uma melhora significativa nas atitudes relacionadas ao meio ambiente. $\mathrm{O}$ respeito aos seres vivos e elementos naturais, a correta caracterização das relações ecológicas básicas foram aspectos percebidos como bem elaborados pelos NEEs.

\section{CONSIDERAÇÕES FINAIS}

O foco maior do projeto foi a elaboração de roteiros de Educação Ambiental para que as dificuldades de relacionamento entre o ser humano e o ambiente possam razoavelmente ser superadas, pois o tratamento integrado das diversas áreas do conhecimento humano, aliado a um compromisso com as relações interpessoais, faz com que haja um aprofundamento na capacidade dos educandos de intervir na realidade e transformá-la. Nesses roteiros realizados em ambientes que possibilitam o contato com a riqueza sócio-ambiental há condições para a formação de cidadãos conscientes, aptos a decidir e a atuar na realidade de modo comprometido com a vida, com o bem estar de cada um e da sociedade, local e global. Para isso, é necessário que, mais do que informações e conceitos, a Educação Ambiental se proponham a trabalhar com atitudes, com formação de valores, com o ensino e a aprendizagem de habilidades e procedimentos.

Os alunos sensibilizaram-se em relação ao meio ambiente e sua importância, conseguindo expor de diferentes maneiras o conceito, algumas relações e os componentes do mesmo. As atividades de educação ambiental realizadas por meio das trilhas interpretativas proporcionaram uma maior aproximação dos alunos NEEs com o meio natural e com os próprios colegas, contribuindo assim com os aspectos afetivos e emocionais dos mesmos. 
Para garantir a acessibilidade de todos os alunos da escola nas atividades da trilha, procurou-se respeitar as diferentes necessidades educativas, eliminando todos os tipos de barreiras físicas e de comunicação. Por se tratar de uma trilha interpretativa para um público portador de NEEs, procurou-se ter cuidado especial com o tipo de informação disponível no folder interpretativo, buscando aliar informação com criatividade e ludicidade, garantindo desta forma aprendizado e desenvolvimento de habilidades.

\section{REFERÊNCIAS}

BATISTA, M. W. et al., Inclusão escolar e deficiência mental: análise da interação social entre companheiros. Estudos de Psicologia, Espírito Santo, 2004, 9(1). 101-111.

CARVALHO,I.C.M. 1998. Em direção ao mundo da vida: interdisciplinaridade e educação ambiental. IPÊ - Instituto de Pesquisas Ecológicas, Brasília, Brasil: 102 p.

DIAS, G. F. Educação Ambiental: princípios e práticas. São Paulo, Gaia, 1992.

DIAS, F. V.; ZANIN, E. M. Eficiência de trilhas interpretativas no Parque Municipal Longines Malinowski, Erechim-RS. Rev. Perspectiva, Erechim, v. 28, p. 29-38, 2004.

GARDNER, H. Inteligências Múltiplas - a teoria na prática. Artmed: Porto Alegre, 1995.

MELLO, N. A; Práticas de Educação Ambiental em Trilhas Ecológicas. Publicação de divulgação do Curso de Ciências Biológicas. UNISC, 2006. Santa Cruz do Sul.

PADUA, S.M.; TABANEZ, M.F. Educação Ambiental Caminhos Trilhados no Brasil. IPÊ, 1997. São Paulo.

TOMAZELLO, M. G. C.; FERREIRA, T. R. C. Educação Ambiental: que critérios adotar para avaliar a adequação pedagógica de seus projetos. Ciência \& Educação. Piracicaba, v.7, n.2, 2001.

SIQUEIRA, L. F. Trilhas interpretativas: Uma vertente responsável do (eco) turismo. Caderno Virtual de turismo, no 14, 2004. Disponível em:

http://www.ivtri.net/caderno/anteriores/14/siqueira/siqueira.pdf. Acesso em 12/06/2011.

VASCONCELLOS, H. S. R. A pesquisa-ação em projetos de Educação Ambiental. In: PEDRINI, A. G. (org). Educação Ambiental: reflexões e práticas contemporâneas. Petrópolis, Vozes, 1997.

ZANIN, E. M. Projeto trilhas interpretativas - a extensão, o ensino e a pesquisa integrados à

conservação ambiental e à educação. Vivências. 1(1):26-35,2006. 